\title{
Design, Optimization, and Mechanical Property Analysis of a Submicrometric Aluminium Alloy Connecting Rod
}

\author{
J. P. Fuertes, J. León, C. J. Luis, D. Salcedo, I. Puertas, and R. Luri \\ Mechanical, Energetics and Materials Engineering Department, Public University of Navarre, Campus de Arrosadia, $s / n$, \\ 31006 Pamplona, Spain
}

Correspondence should be addressed to I. Puertas; inaki.puerta@unavarra.es

Received 16 March 2015; Revised 23 June 2015; Accepted 15 July 2015

Academic Editor: Claude Estournès

Copyright (C) 2015 J. P. Fuertes et al. This is an open access article distributed under the Creative Commons Attribution License, which permits unrestricted use, distribution, and reproduction in any medium, provided the original work is properly cited.

Ultrafine grained materials have a great deal of both scientific and technological interest because they allow outstanding properties to be obtained. An improvement in the mechanical strength and in the ductility and a better fatigue behaviour are properties to be expected with these materials. However, in spite of the great number of scientific publications that deals with the mechanical property improvement, the number of practical applications of these materials is scant. In this present research work, equal channel angular pressing (ECAP) is used as a severe plastic deformation process (SPD) to obtain billets which are subsequently isothermally forged to obtain a connecting rod with submicrometric grain size. The optimization of the design process is shown as well as the die design. The objective variables to be fulfilled are the correct filling of the die and the required force to obtain the part. Moreover, a comparison is also included between the mechanical properties thus obtained and those obtained with traditional methods. Moreover, optical and SEM micrographs are also included in this research work.

\section{Introduction}

The main aim of severe plastic deformation (SPD) processes is to obtain ultrafine grained materials (UFG). The improvements in the mechanical properties of these previously SPDprocessed materials can be quantified in terms of the increase in the yield stress, ultimate tensile strength, and fatigue limit, among many others. Moreover, it is possible to obtain superplasticity at moderate forging temperatures. Within the SPD process developed over these past few years, one of the most widely studied that provides better mechanical properties is the one known as equal channel angular extrusion or pressing (ECAP), which was firstly proposed by Segal in the former Soviet Union [1]. This SPD process is, without any doubt, one of the most widely known. In addition, there are other SPD processes such as High Pressure Torsion (HPT) [2], Repetitive Corrugation and Straightening (RCS) [3], and Cyclic Extrusion Compression (CEC) [4]. These processes can be grouped as discontinuous processes, with the drawbacks of low velocity and, as a consequence of this, a reduced productivity. Nevertheless, the improvement in the mechanical properties is higher than that obtained with the employment of continuous SPD processes such as Accumulative Roll Bonding (ARB) [5] and ECAP-Conform [6]. On the other hand, it can be observed in the recent bibliography that there is a trend toward combining two or more existing processes in the way of [7], where hot isostatic pressing process (HIT) is combined with dynamic severe plastic deformation (DSPD).

Several materials have been processed by using the previously mentioned processes such as aluminium alloys, copper alloys, and titanium alloys [8]. In addition, these processes have been applied to nonmetallic materials such as high-density polyethylene (HDPE) [9]. In [10], it is possible to find a research study on the evolution of the mechanical properties for four aluminium alloys, where two of them are similar to those employed in this present research work. The authors employ two different ECAP dies. One of them is with an intersection angle of $90^{\circ}$ and the other is with $120^{\circ}$. The materials are processed once $(\mathrm{Nl})$ and a higher grain size reduction is observed by using the $90^{\circ}$ configuration [10]. As the cross section of the SPD-processed materials does not change significantly, it is possible to increase these deformation values by processing again the billets (N2) by 
ECAP. As a consequence of the reduced dimensions of the ECAP'ed billets and in spite of the improvement in the mechanical properties of the ECAP'ed materials, there exist very few practical applications dealing with parts manufactured from previously ECAP'ed materials. Within the existing applications in the bibliography, it is worth mentioning that there is a manufacturing application of blades by isothermal forging with a configuration similar to that employed in the Francis turbines, where the complex geometry requires a good plastic flow of the material [11]. The advantages of forging the parts at warm temperatures are demonstrated by using isothermal forming. Although at these forging temperatures a loss in the mechanical properties of the ECAP'ed billets is obtained, this leads to a better plastic flow of the material and to a better filling of the die compared to that obtained in the conventional forging. This is very important when parts with complex geometries are required to be manufactured. Moreover, these studies show by means of microhardness measurements that there exists a significant increase in the microhardness of the thus obtained parts compared to those obtained by using conventional methods from annealed materials. In [12], an impeller with reduced dimensions is developed by using a magnesium alloy. In [13], a manufacturing process followed to obtain bolts from materials previously ECAP'ed is shown. The authors propose a system that allows a higher production rate to be obtained.

A comprehensive study on the microhardness obtained for a screw made of AA1050 can be seen in [14] with different ECAP routes up to 3 passages (N3). The most significant results include on the one hand the increase in the hardness of the screw with the first ECAP passage and on the other hand the fact that the screws after route $A$ are those which exhibit higher microhardness values both at the head and at the body. In this regard, it is worth mentioning that route $\mathrm{A}$ imparts a high anisotropy degree within the material, which leads to a lack of homogeneity in the mechanical properties of the screws. Although most of the research studies on parts made from nanostructured materials by SPD deal with forging, there are also some studies on machinability. In $[15,16]$, the authors analyse the surface finish on parts machined from material which is previously ECAP'ed by using commercially pure copper and AA6082, respectively. The authors analyse the influence of different cutting tools and the number of ECAP passages by using routes $\mathrm{B}$ and $\mathrm{C}$.

This present research study deals with the isothermal forging of a connecting rod manufactured by using AA1050 and AA5083 which have been previously ECAP'ed with two passages using route $C$. Hence, it is necessary to perform a previous study on the forgeability of the parts in order to be able to develop both the design of the connecting rod and the forging dies. Several studies that deal with the design optimization of connecting rods by using finite element simulations may be found in the bibliography but these are about fatigue [17] and the reduction in weight and inertial forces [18], among other mechanical parameters. Nevertheless, there are very few studies that deal with the analysis of the material flow during the forging process and the reduction of the required processing force.
One of the objectives to be reached in this research work is to get a good filling of the forging dies with the lowest processing force. Another objective is that the plastic flow of the material in all sections of the connecting rod is adequate, thus preventing the existence of zones with excessive accumulation of damage.

In [19], a research study which deals with the different steps involved in the hot forging of a connecting rod is shown by using finite elements simulations. In this case, the authors pay attention to the number of elements employed for the simulations in order to achieve an optimal time calculation. In order to obtain accurate FEM results, remeshing is used in those sections with very complex geometry. As was previously mentioned, in this present research study two connecting rods made from AA1050 and AA5083 previously ECAP'ed are manufactured with the objective of obtaining submicrometric grain size in the parts to be forged as well as to improve their mechanical properties. Furthermore, it is shown that it is feasible to develop mechanical components with submicrometric structure and with improved mechanical properties in comparison to those obtained by using conventional methods, which usually consist in forging the parts starting from annealed materials.

\section{Set-Up of the Experimentation and FEM Modelling}

In this present section, experimentation procedures are firstly presented and subsequently the design of both the connecting rod and the dies is shown.

2.1. Experimentation Procedures. As indicated, a study on the isothermal forging of a circular connecting rod is carried out from material previously ECAP'ed. To this end, two aluminium alloys are used: AA1050 and AA5083. In both study cases, the initial material is both ECAP'ed and annealed material. It is also intended to make a comparison between the mechanical properties of both starting materials with the aim of assessing the improvement in the mechanical properties of the part forged starting from material with submicrometric grain size.

To carry out this study, a series of tests are planned taking into account as study variables the number of ECAP passages and the temperature at which the isothermal forging takes place, as is shown in Table 1. The temperature values selected for the isothermal forging of the AA5083 connecting rods are higher than those manufactured from AA1050 because the first is an aluminium alloy with higher mechanical strength. The values are selected taking the results obtained in [20] into consideration. Once the forging tests are carried out, microhardness measurements are taken at those zones shown as required after performing the simulations. The experimental conditions for the microhardness to be measured are based on the ISO 6507-1:2005 norm [21], where, at first, there is a $4 \mathrm{~s}$ period for the penetrator approach, followed by the application of a $300 \mathrm{~g}$ load during $10 \mathrm{~s}$ and, finally, there is another $4 \mathrm{~s}$ period for the penetrator withdrawal. 


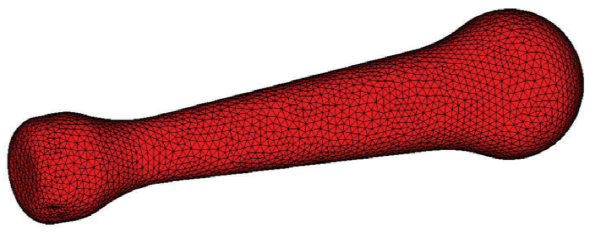

(a) Initial billet

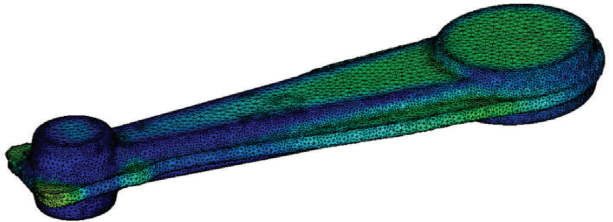

(b) Preform

Figure 1: Meshing of the billets.

TABLE 1: Experimental forging tests performed.

\begin{tabular}{lcc}
\hline Material & ECAP passages & Temperature $\left({ }^{\circ} \mathrm{C}\right)$ \\
\hline \multirow{4}{*}{ AA1050 } & N0 & 25 \\
& & 100 \\
& \multirow{2}{*}{ N2 } & 150 \\
& & 25 \\
& & 100 \\
AA5083 & N0 & 150 \\
\hline & & 150 \\
& & 200 \\
& N2 & 250 \\
& & 150 \\
& & 200 \\
\end{tabular}

Cylindrical billets of $20 \mathrm{~mm}$ in diameter and $120 \mathrm{~mm}$ in length are ECAP'ed at a velocity of $25 \mathrm{~mm} / \mathrm{min}$. Two ECAP passages (N2) are carried out over each billet with route $\mathrm{C}$ (where this means that, after ECAP passage, the billet is rotated $180^{\circ}$ with respect to its longitudinal axis). In order to carry out the forging process of the connecting rods, a hydraulic press is employed with a maximum pressing force of $3000 \mathrm{kN}$. The press is equipped with a die holder system. The die holders have a series of heating resistances which transmit the heat to the forging dies until the desired temperature for the isothermal forging to be carried out is reached. Due to the high amount of flow the material requires for the connecting rod forging, the design of both the forging dies and the initial billet geometry is dealt with in this research study in such a way that the die filling is optimised with the lowest value for the required forging force.

\subsection{Mechanical Design Optimization for the Isothermal Forg-} ing Dies. The first step for the connecting rod manufacturing is to design both the die and the initial billet geometries. A first objective to be fulfilled is that the connecting rod may be forged in two stages in such a way that both the preform (first stroke) and the final connecting rod (second stroke) correctly fill the die not exceeding the maximum load for the press, which is $3000 \mathrm{kN}$. In order to do this, a predesign of both the initial billet and the first stroke forging die is taken as a first approach, and then it is observed if the two previously mentioned conditions are fulfilled. At first, the process to be

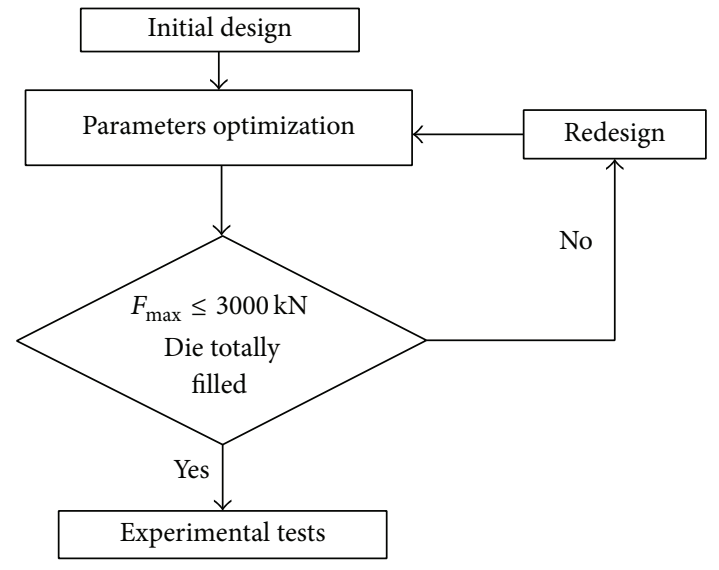

FIGURE 2: Optimization procedure. simulated is considered as a three-dimensional forging with flash, where both upper and bottom dies are rigid and the billet is a deformable body. In the case of this present research work, Shear's type friction is taken. As a consequence of the high strain values, the elements are excessively distorted along the simulation and thus remeshing is applied during the FEM simulation process. The type of element used has four integration points with an initial edge size of $1 \mathrm{~mm}$ for the preform and an edge size of $0.7 \mathrm{~mm}$ for the second stroke. This leads to a total of 11000 elements for the first stroke, Figure 1(a), and a total of 63000 elements in the case of the second stroke, Figure 1(b). Finally, because of the different study cases taking the design variables into consideration (material and temperature), the most disadvantageous case is decided to be simulated, that is to say, N2 state AA5083 as starting material and forging at room temperature. If the requirements of correct filling and not exceeding the maximum force are fulfilled in this case, these will also be fulfilled in the remaining cases.

2.2.1. Mechanical Design Optimization. Figure 2 shows the flow diagram carried out to find the optimum design for each of the two forging stages required in the manufacturing of the connecting rod.

The fact that the dimensions of the billets to be ECAP'ed cannot be as long as is desired limits the subsequent design of the connecting rod. In addition, with the aim of getting starting material with the highest level of strain homogeneity, 


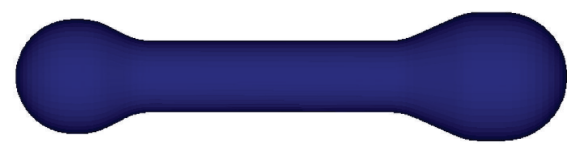

(a) Initial billet

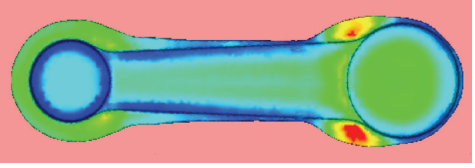

(b) Unfilled preform

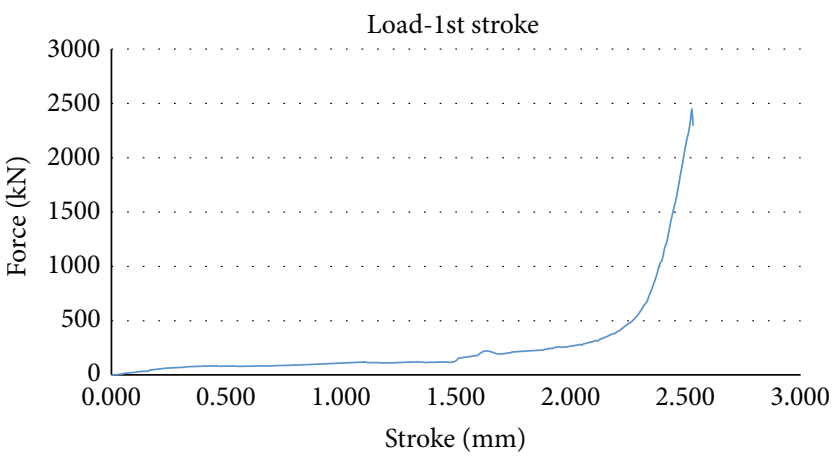

(c) Load-1st stroke curve

FIgURE 3: First design for the first stroke.

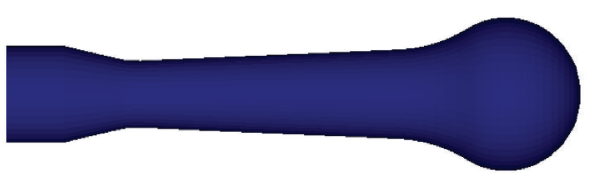

(a) Initial billet

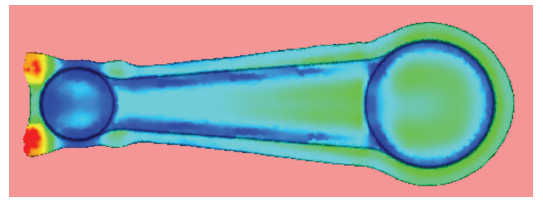

(b) Preform totally filled

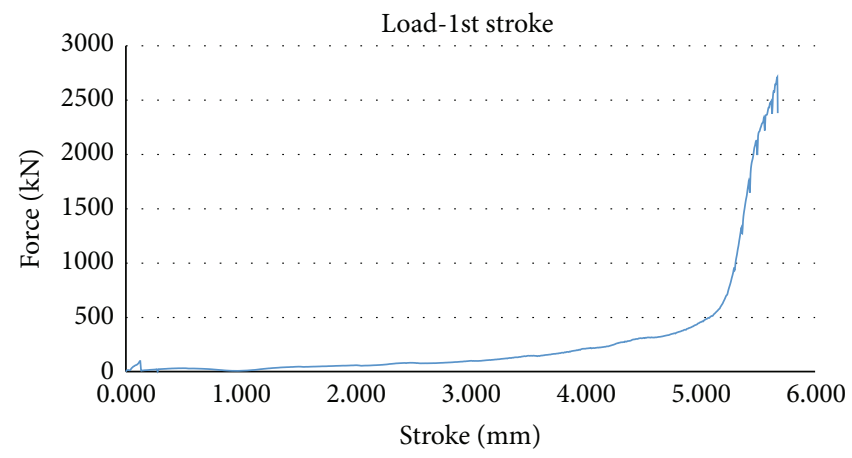

(c) Load-1st stroke curve

FIGURE 4: Second design for the first stroke.

the ECAP'ed billets are machined from its initial diameter of $20 \mathrm{~mm}$ down to a final diameter of $18 \mathrm{~mm}$.

2.2.2. Preform Optimization. As initial geometry for the preform, the design consists in a billet with spherical shape in both heads (Figure 3(a)) so that the material may have a better flow inside the forging die.

Nevertheless, as can be observed in Figure 3(b), the filling of the die is incomplete after the first forging stage and there is a surplus of flash not only at the foot but also at the joint between the body and the head of the connecting rod. Therefore, in spite of the fact that the force value is within the press capacity as can be observed in Figure 3(c), it is necessary to make a redesign since the second condition is not fulfilled.
For the second design, the initial billet dimensions are reduced in size at the zone where the connecting rod foot is forged and on the contrary they are increased at the head zone. Moreover, a geometry in the shape of a truncated cone is designed for the body and a flat surface is introduced at one of the ends of the initial billet.

This new design for the initial billet is shown in Figure 4(a) and it may be now observed that the material completely fills the preform die after the first forging stroke. However, the design of a flat surface at the connecting rod foot (see Figure 4(b)) leads to a nonhomogeneous material flow. On the other hand, it is observed from the simulation of the load-stroke curve that the force does not exceed the press capacity, as is shown in Figure 4(c). Therefore, following the 


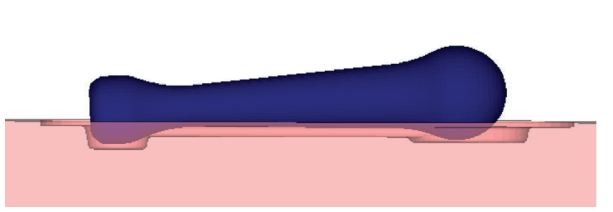

(a) Initial billet

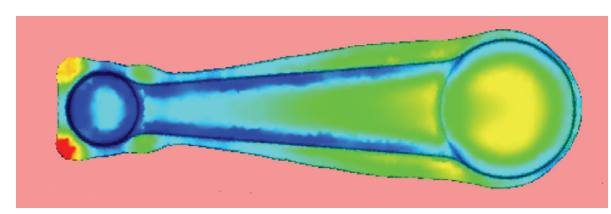

(b) Preform totally filled

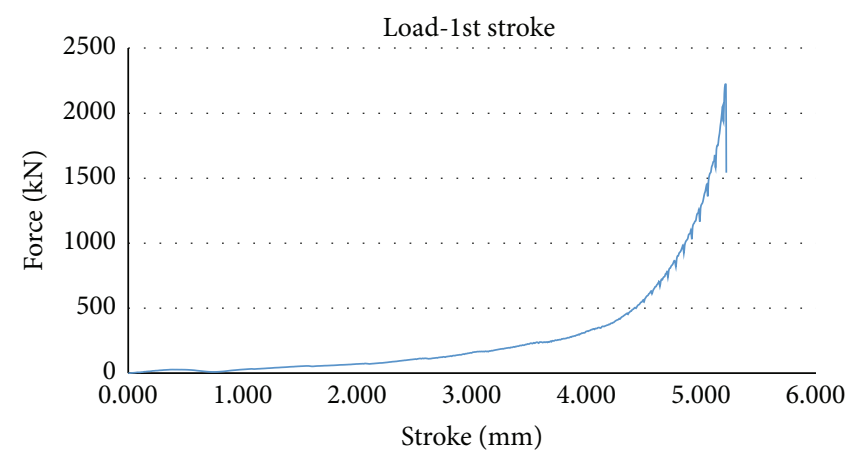

(c) Load-1st stroke curve

FIgURE 5: Optimum design for the preform.

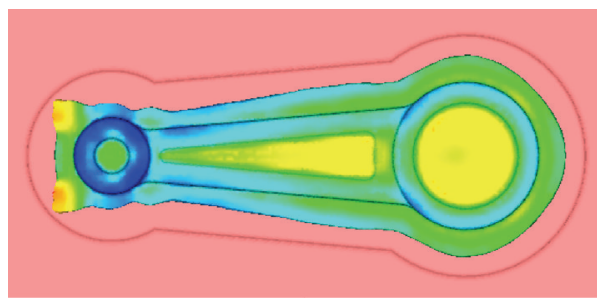

(a) Final connecting rod

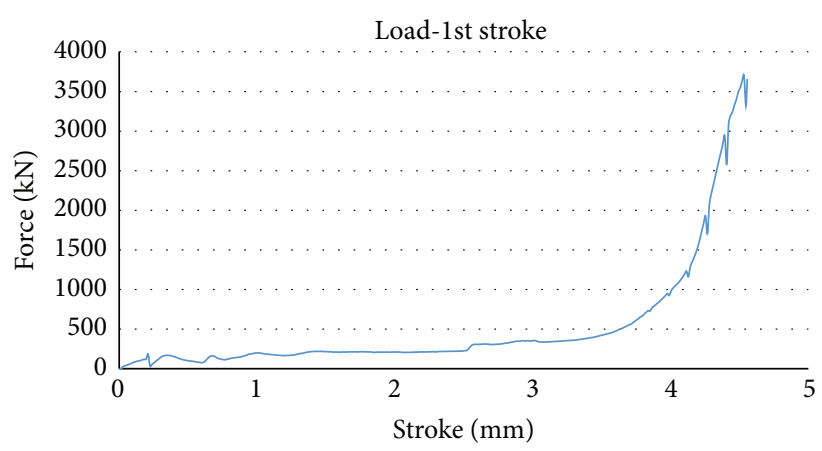

(b) Load-stroke curve

FIgURE 6: First design for the second stroke.

design optimization procedure shown in Figure 2, this initial billet design may be considered as correct. Nevertheless, a new redesign which reduces the flash obtained is made in order to decrease the force for the second stroke down to a minimum level.

The new billet redesign includes a fillet radius for the flat surface and a slight reduction in size for the semisphere dimensions. Figure 5(a) shows the initial billet placed on the bottom forging die. It is observed from Figure 5(b) that the die filling is complete and there is a lesser amount of flash, which leads to a reduction in the forging force and thus to reaching one of the desired objectives. Therefore, this is considered to be the optimum design for the preform to be forged.

2.2.3. Connecting Rod Optimization. Once the optimum design for the preform is reached, the same procedure is applied to obtain the optimum design for the die cavity which allows the circular connecting rod to be manufactured. As can be observed in Figure 6(a), there is a surplus of flash for the final connecting rod which leads to an increase in the force up to a value that exceeds the press capacity (see Figure 6(b)). Therefore, a redesign is needed in the case of the final forging dies.

In order to decrease the flash volume, the head dimension is reduced but at the same time not varying the geometry for the connecting rod foot. Nevertheless, the reduction of the latter is excessive, as can be observed in Figure 7(a), thus leading to two zones with an incomplete die filling. In spite of the fact that the load-stroke curve indicates that the process is within the force requirements (see Figure $7(b)$ ), a new redesign is needed in order to improve the die filling at the connecting rod head.

After the new redesign, a complete die filling is achieved, as can be observed in Figure 8(a). In addition, the load-stroke curve shows a good fitting for the forging force, which is lower than the press capacity. Therefore, the optimization 


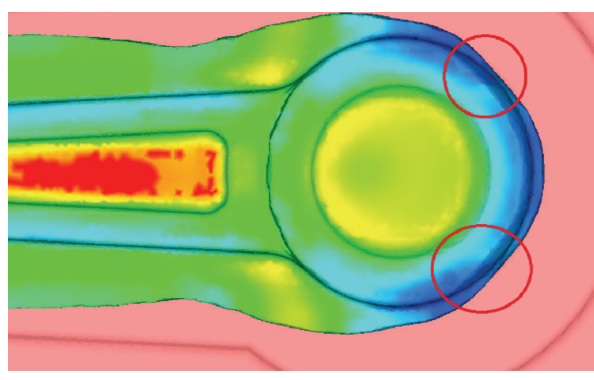

(a) Final connecting rod

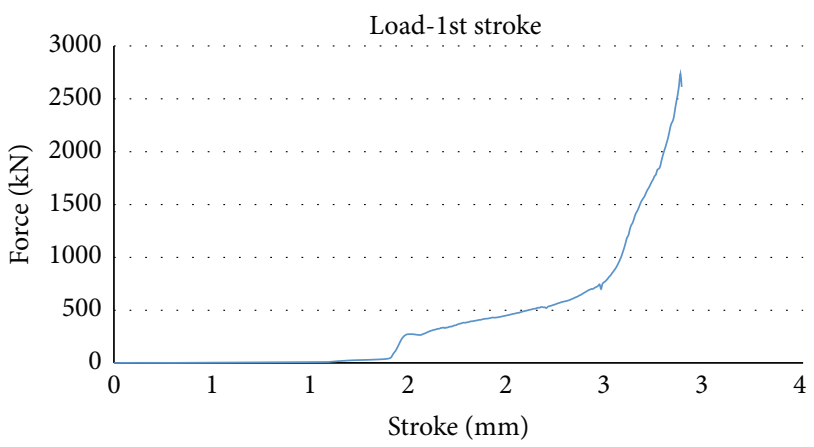

(b) Load-stroke curve

FIgURE 7: Second design for the second stroke.

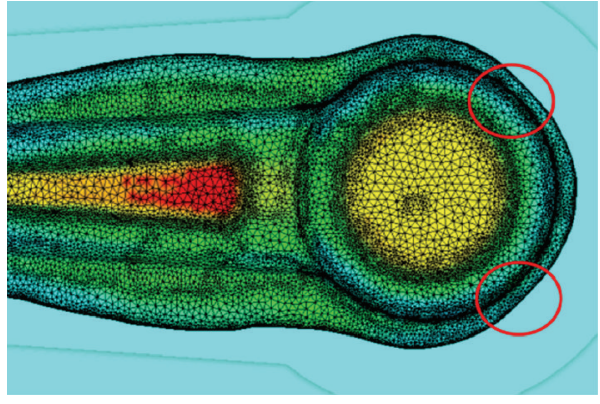

(a) Final connecting rod

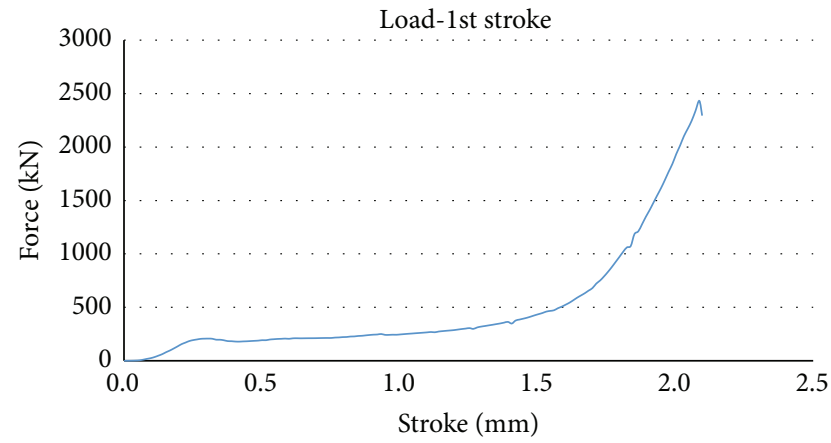

(b) Load-stroke curve

FIGURE 8: Final design for the second stroke.

process is considered to be finished with this last redesign. As can be observed in Figure 8, a complete filling of the die is achieved with the new redesign and hence this is the final design considered in this present study.

Once the geometry optimum design is reached for both the initial billet and the forging dies, the next step is to manufacture them.

\section{Manufacturing of Mechanical Components}

As was previously mentioned, once the optimum die geometry is designed based on the optimization of both the die filling and the forging force, the manufacturing of them is dealt with in order to study the improvements obtained in the mechanical properties when ECAP'ed billets are used as starting material.

The forging process is accomplished in two strokes and at the temperature values shown in Table 1. In the case of the first stroke, a flat preform is obtained with no holes and no ribs. It is in the second stroke when the final geometry is achieved. The forging process of both stages is performed at a velocity of $50 \mathrm{~mm} / \mathrm{min}$.

The set of dies are previously heated at the desired temperature thanks to heating resistances and once this temperature value is achieved, the billet shown in Figure 9(a) is placed on the bottom die and a period of five minutes is taken so that the billet may reach the forging die temperature.
At this precise moment, the first stroke is carried out with the forging die shown in Figure 9(b) and thus the preform shown in Figure 9(c) is shown. Subsequent to the first stroke, the preform obtained is placed on the final forging die shown in Figure 9(d) and the second and ultimate forging stroke is carried out.

Figure 9(e) shows the connecting rod forged. In order to finish the part, it is necessary to make the two holes for both the head and the foot of the connecting rod and also to machine the edges so that the flash may be removed. In order to carry out both isothermal forging stages, a dry lubricant with polytetrafluoroethylene (PTFE) is employed.

In order to analyse the improvement in the mechanical properties achieved in the material, microhardness measurements are taken on the connecting rods. Cross sections to be studied are selected taking the strain results obtained in the FEM simulations into consideration, as can be observed in Figure 10(a). Two of the zones selected correspond to the head and to the foot since these are the points with the lowest cross section. Another cross section is the zone with the highest strain value, that is to say, the rib at the zone close to the head. Five measurements are taken in each cross section taking advantage of the component symmetry and these are distributed as a function of the strain value obtained, as can be observed in Figure 10(b) to Figure 10(d). From all the values measured, the average and the standard deviation values are calculated in each study zone in order to make a comparison between the different tests. 


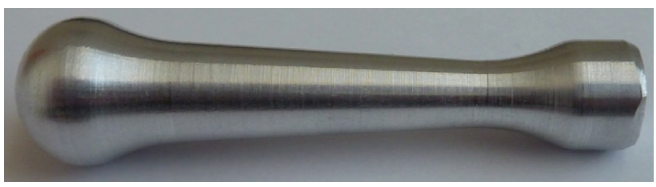

(a) Initial billet

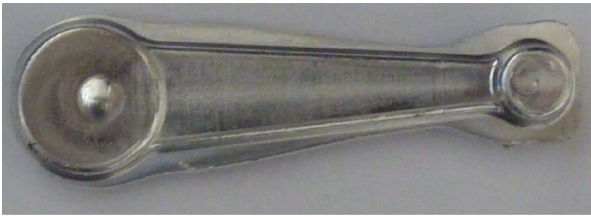

(c) Preform

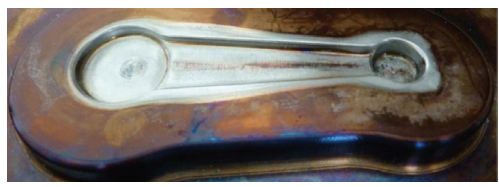

(b) Preform die

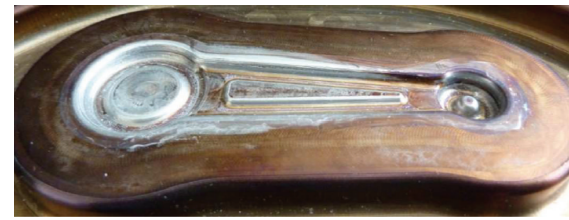

(d) Connecting rod die

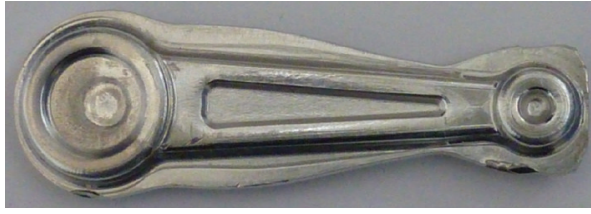

(e) Connecting rod

FIGURE 9: Steps followed for the manufacturing of the connecting rod.

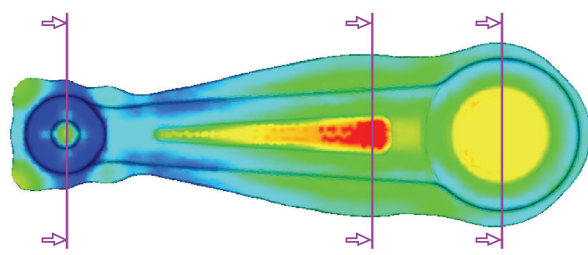

(a) Total equivalent plastic strain distribution

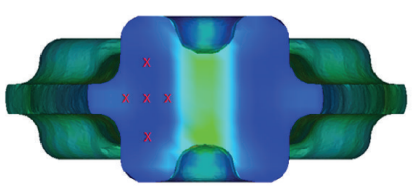

(b) 1st section

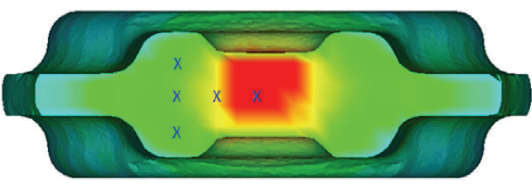

(c) 2nd section

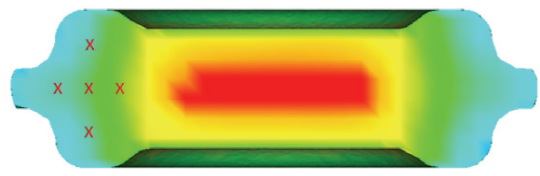

(d) 3rd section

Figure 10: Sections chosen for the microhardness study.

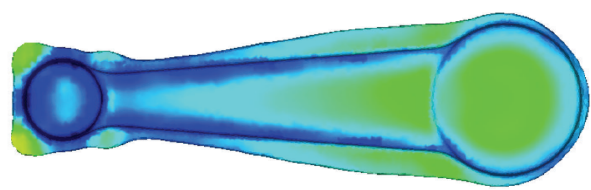

(a) Simulated preform

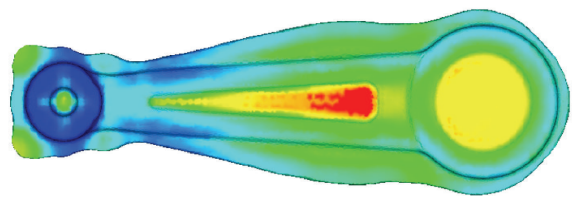

(c) Simulated connecting rod

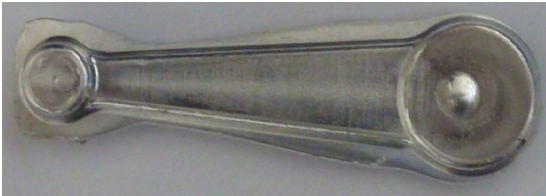

(b) Experimental preform

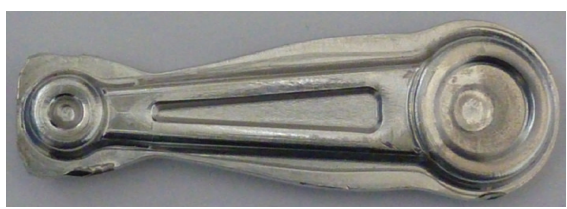

(d) Experimental connecting rod

FIGURE 11: Simulation versus real test. 


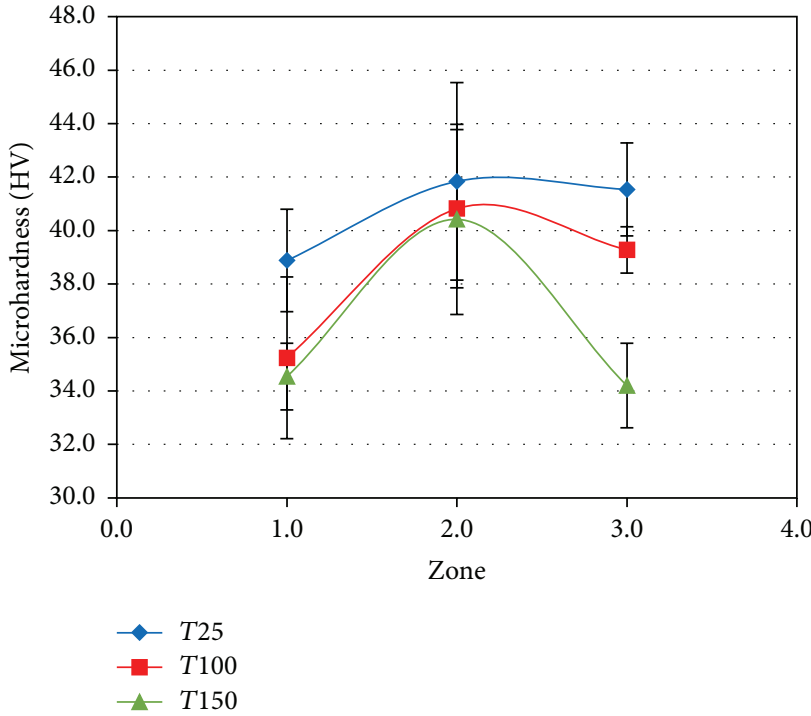

(a) N0

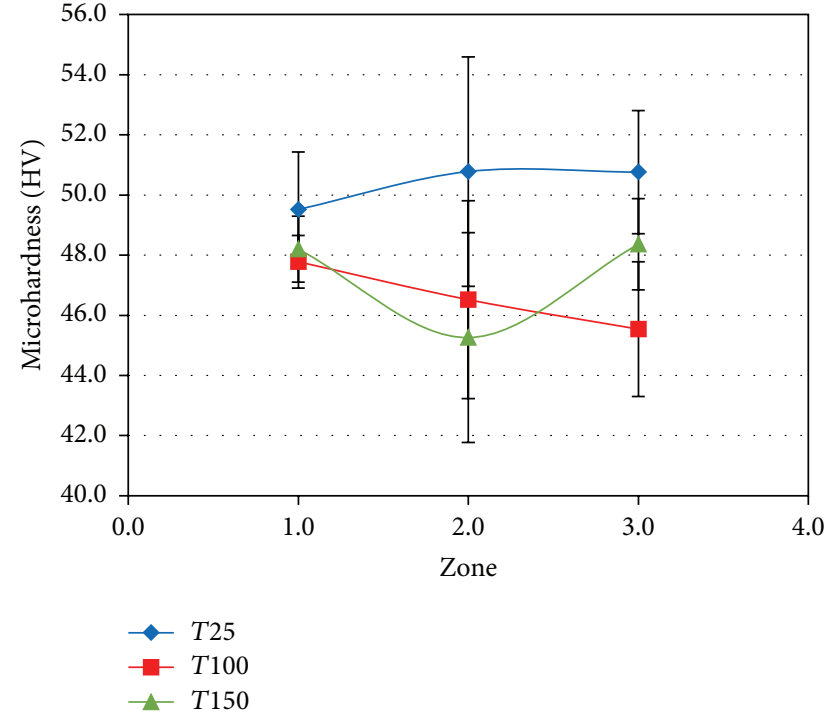

(b) $\mathrm{N} 2$

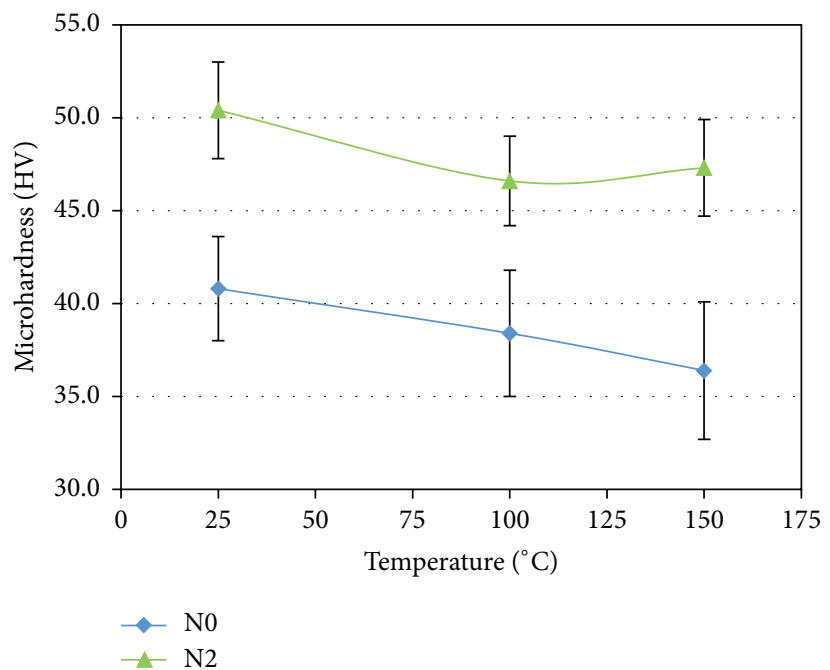

(c) N0 versus $\mathrm{N} 2$

Figure 12: Microhardness at different temperatures in the selected cross sections for AA1050.

\section{Discussion of Results}

Once the connecting rods are manufactured by isothermal forging and the microhardness study is carried out, the analysis of results is dealt with.

Figure 11 shows the high level of agreement between the simulations with the final design and the real tests. Specifically, with the third design modification for the first forging stroke, it is verified that the head zone design is very adequate since the complete cavity filling is achieved with the minimum amount of flash.

The results for the microhardness measurements obtained in each of the cases under consideration are shown in Tables 2 and 3, as well as their corresponding average and standard deviation values (SDV). The highest standard deviation value takes place at zone 2 , which is the least homogeneous, since this central part accumulates a higher strain value due to the rib forging. As was expected, the lowest value of microhardness corresponds to the non-ECAP'ed AA1050 connecting rod forged at $150^{\circ} \mathrm{C}$ (AA1050 N0 T150).

The connecting rod with the highest hardness value is that forged at $150^{\circ} \mathrm{C}$ from previously ECAP'ed AA5083 as Table 3 shows. Figure 12 shows the microhardness graphs at the three cross sections selected obtained for AA1050 forged at different temperature values in the two starting states. As is observed in Figure 12(a), in the case of the non-ECAP'ed AA1050, as the forging temperature increases, microhardness decreases. It is at the central zone where there is a lesser variation between the three cases, whereas, at zone 1 and zone 3 , the difference between the forging at room temperature and at $150^{\circ} \mathrm{C}$ is of $18 \%$. In the case of the previously ECAP'ed AA1050, the graphs obtained are shown in Figure 12(b). 
TABLE 2: Microhardness values for all the AA1050 connecting rods.

\begin{tabular}{|c|c|c|c|c|c|c|c|c|}
\hline \multicolumn{3}{|c|}{ AA1050 N0 T25 } & \multicolumn{3}{|c|}{ AA1050 N0 T100 } & \multicolumn{3}{|c|}{ AA1050 N0 T150 } \\
\hline Zone 1 & Zone 2 & Zone 3 & Zone 1 & Zone 2 & Zone 3 & Zone 1 & Zone 2 & Zone 3 \\
\hline 38.5 & 40.7 & 39.9 & 37.2 & 43.1 & 38.5 & 35.8 & 43.2 & 32.6 \\
\hline 37.7 & 37.6 & 41.4 & 33.7 & 40.8 & 39.8 & 33.4 & 36.6 & 35.3 \\
\hline 39.9 & 39.5 & 43.9 & 30.6 & 35.9 & 38.2 & 33.2 & 36.5 & 32.6 \\
\hline 36.7 & 45.5 & 42.6 & 37.5 & 41.1 & 40.1 & 34.5 & 42.3 & 36.1 \\
\hline 41.6 & 45.9 & 39.9 & 37.2 & 43.2 & 39.8 & 35.8 & 43.5 & 34.4 \\
\hline 38.9 & 41.8 & 41.5 & 35.2 & 40.8 & 39.3 & 34.5 & 40.4 & 34.2 \\
\hline 1.9 & 3.7 & 1.7 & 3.0 & 3.0 & 0.9 & 1.3 & 3.6 & 1.6 \\
\hline \multicolumn{3}{|c|}{ Mean: 40.8, SDV: 2.8} & \multicolumn{3}{|c|}{ Mean: 38.4, SDV: $\mathbf{3 . 4}$} & \multicolumn{3}{|c|}{ Mean: 36.4, SDV: 3.7} \\
\hline \multicolumn{3}{|c|}{ AA1050 N2 T25 } & \multicolumn{3}{|c|}{ AA1050 N2 T100 } & \multicolumn{3}{|c|}{ AA1050 N2 T150 } \\
\hline Zone 1 & Zone 2 & Zone 3 & Zone 1 & Zone 2 & Zone 3 & Zone 1 & Zone 2 & Zone 3 \\
\hline 50.1 & 50.0 & 53.0 & 47.8 & 43.8 & 46.8 & 47.5 & 45.7 & 48.9 \\
\hline 47.1 & 48.9 & 47.5 & 48.7 & 45.5 & 42.3 & 49.2 & 44.9 & 46.4 \\
\hline 48.0 & 46.3 & 50.4 & 48.6 & 43.3 & 46.6 & 46.7 & 39.6 & 49.2 \\
\hline 50.7 & 56.4 & 51.7 & 46.8 & 49.6 & 47.8 & 48.4 & 48.6 & 50.1 \\
\hline 51.7 & 52.3 & 51.2 & 47.0 & 50.4 & 44.2 & 49.2 & 47.5 & 47.2 \\
\hline 49.5 & 50.8 & 50.8 & 47.8 & 46.5 & 45.5 & 48.2 & 45.3 & 48.4 \\
\hline 1.9 & 3.8 & 2.1 & 0.9 & 3.3 & 2.2 & 1.1 & 3.5 & 1.5 \\
\hline \multicolumn{3}{|c|}{ Mean: 50.4, SDV: 2.6} & \multicolumn{3}{|c|}{ Mean: 46.6, SDV: 2.4} & \multicolumn{3}{|c|}{ Mean: 47.3, SDV: 2.6} \\
\hline
\end{tabular}

TABLE 3: Microhardness values for all the AA5083 connecting rods.

\begin{tabular}{|c|c|c|c|c|c|c|c|c|}
\hline \multicolumn{3}{|c|}{ AA5083 N0 T150 } & \multicolumn{3}{|c|}{ AA5083 N0 T200 } & \multicolumn{3}{|c|}{ AA5083 N0 T250 } \\
\hline Zone 1 & Zone 2 & Zone 3 & Zone 1 & Zone 2 & Zone 3 & Zone 1 & Zone 2 & Zone 3 \\
\hline 98.1 & 109.5 & 118.6 & 97.6 & 98.2 & 107.4 & 89.5 & 94.1 & 96.6 \\
\hline 93.7 & 103.0 & 106.1 & 96.0 & 104.0 & 110.4 & 90.5 & 96.3 & 92.5 \\
\hline 98.0 & 112.0 & 114.5 & 96.2 & 95.8 & 107.2 & 89.0 & 97.1 & 96.6 \\
\hline 94.3 & 120.5 & 118.7 & 94.9 & 118.9 & 106.5 & 89.2 & 112.7 & 97.4 \\
\hline 97.6 & 117.0 & 111.8 & 98.1 & 123.4 & 107.2 & 92.9 & 99.5 & 104.1 \\
\hline 96.3 & 112.4 & 113.9 & 96.6 & 108.1 & 107.7 & 90.2 & 99.9 & 97.4 \\
\hline 2.2 & 6.8 & 5.3 & 1.3 & 12.4 & 1.5 & 1.6 & 7.4 & 4.2 \\
\hline \multicolumn{3}{|c|}{ Mean: 107.6, SDV: 9.5} & \multicolumn{3}{|c|}{ Mean: 104.1, SDV: 8.7} & \multicolumn{3}{|c|}{ Mean: 95.9, SDV: 6.3} \\
\hline \multicolumn{3}{|c|}{ AA5083 N2 T150 } & \multicolumn{3}{|c|}{ AA5083 N2 T200 } & \multicolumn{3}{|c|}{ AA5083 N2 T250 } \\
\hline Zone 1 & Zone 2 & Zone 3 & Zone 1 & Zone 2 & Zone 3 & Zone 1 & Zone 2 & Zone 3 \\
\hline 120.4 & 128.4 & 128.4 & 128.2 & 126.9 & 127.4 & 111.2 & 110.0 & 101.7 \\
\hline 116.2 & 132.0 & 126.4 & 115.6 & 126.0 & 121.7 & 109.0 & 109.4 & 103.4 \\
\hline 125.1 & 122.0 & 124.9 & 124.3 & 124.1 & 125.0 & 110.3 & 105.6 & 91.0 \\
\hline 121.9 & 142.1 & 129.8 & 119.8 & 130.5 & 130.7 & 111.5 & 114.5 & 90.1 \\
\hline 117.3 & 146.2 & 129.2 & 122.3 & 125.7 & 130.8 & 110.5 & 115.8 & 103.5 \\
\hline 120.2 & 134.1 & 127.7 & 122.0 & 126.6 & 127.1 & 110.5 & 111.1 & 97.9 \\
\hline 3.6 & 9.9 & 2.0 & 4.7 & 2.4 & 3.9 & 1.0 & 4.1 & 6.8 \\
\hline \multicolumn{3}{|c|}{ Mean: 127.4, SDV: $\mathbf{8 . 2}$} & \multicolumn{3}{|c|}{ Mean: 125.3, SDV: $\mathbf{2 . 6}$} & \multicolumn{3}{|c|}{ Mean: 106.5, SDV: 7.6} \\
\hline
\end{tabular}




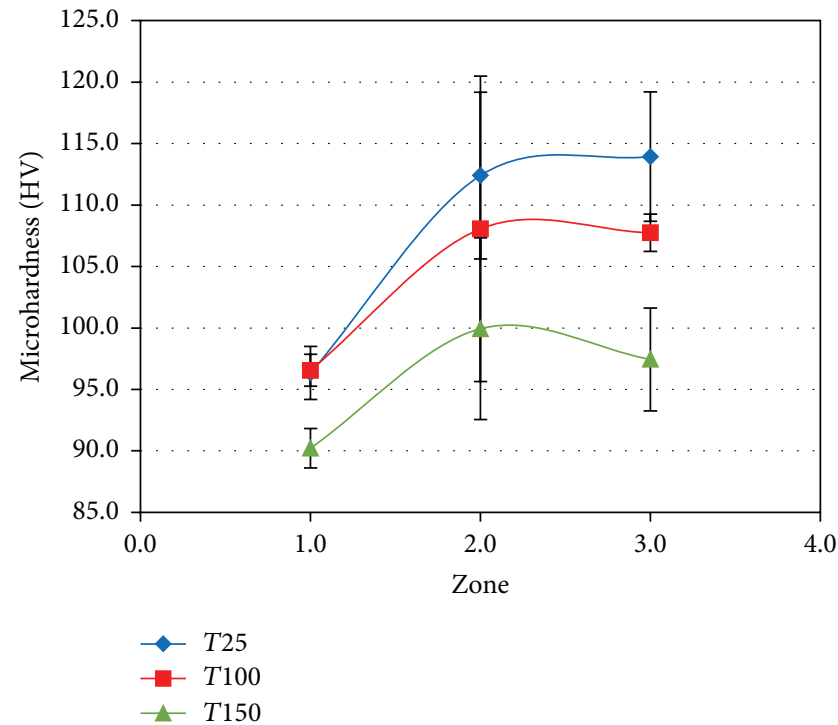

(a) N0

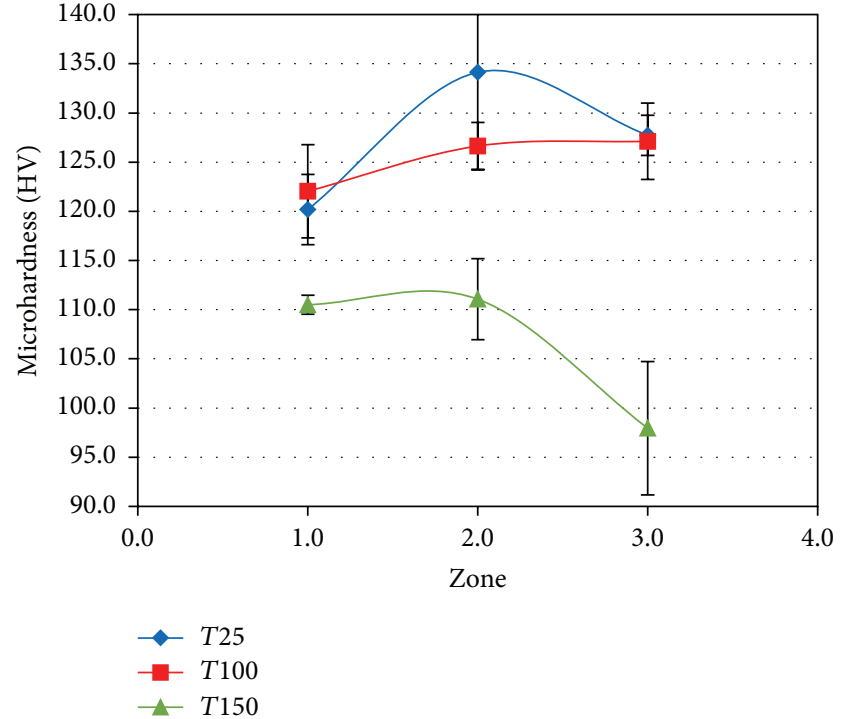

(b) $\mathrm{N} 2$

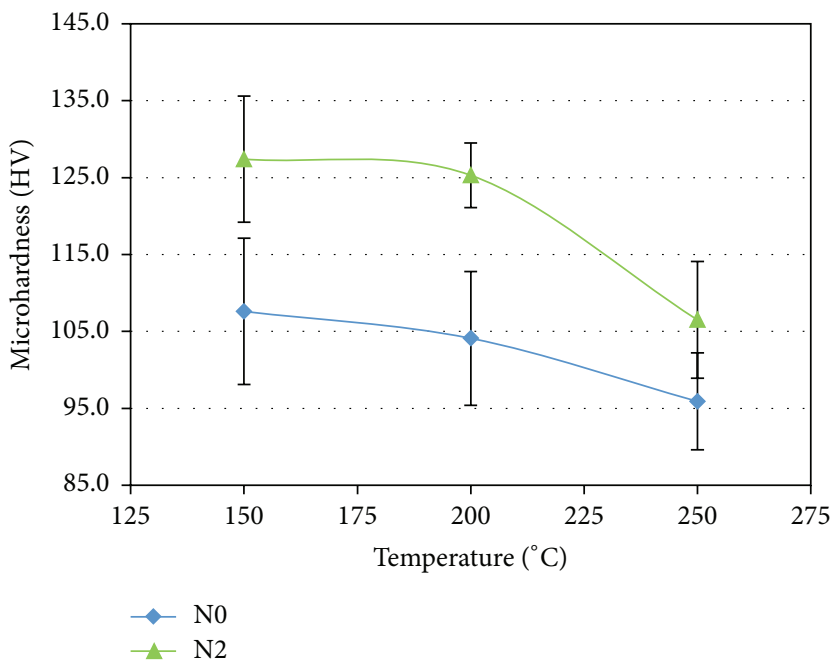

(c) N0 versus $\mathrm{N} 2$

FIGURE 13: Microhardness at different temperatures in the selected cross sections for AA5083.

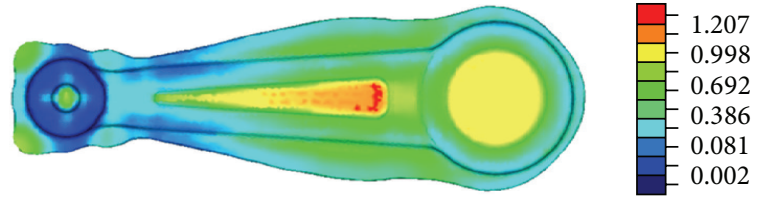

(a) Connecting rod forged at $25^{\circ} \mathrm{C}$ from AA1050 in N0 state

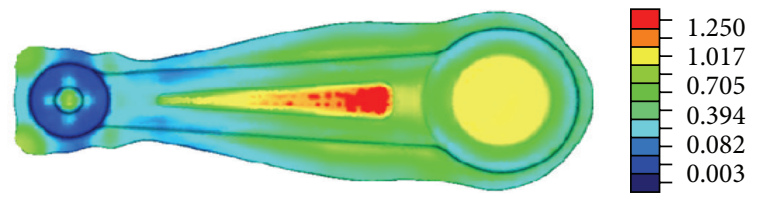

(c) Connecting rod forged at $150^{\circ} \mathrm{C}$ from AA5083 in N0 state

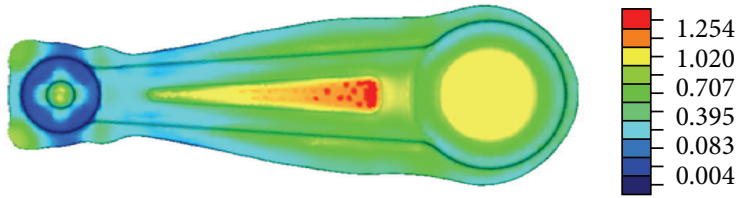

(b) Connecting rod forged at $25^{\circ} \mathrm{C}$ from AA1050 in N2 state

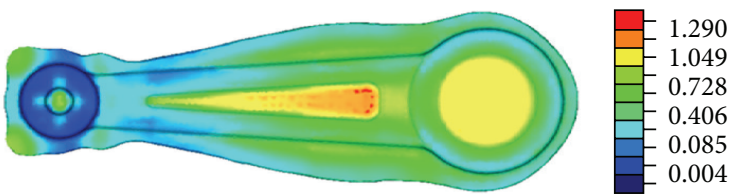

(d) Connecting rod forged at $150^{\circ} \mathrm{C}$ from AA5083 in N2 state

FIGURE 14: Total equivalent plastic strain for the optimum connecting rods simulated. 


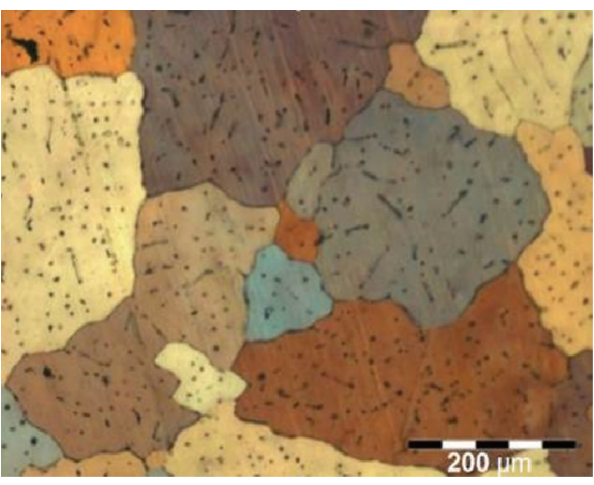

(a) AA1050 in N0 state

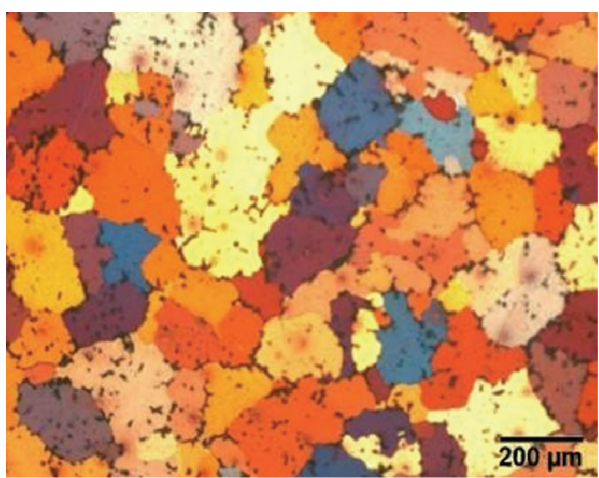

(c) AA5083 in N0 state

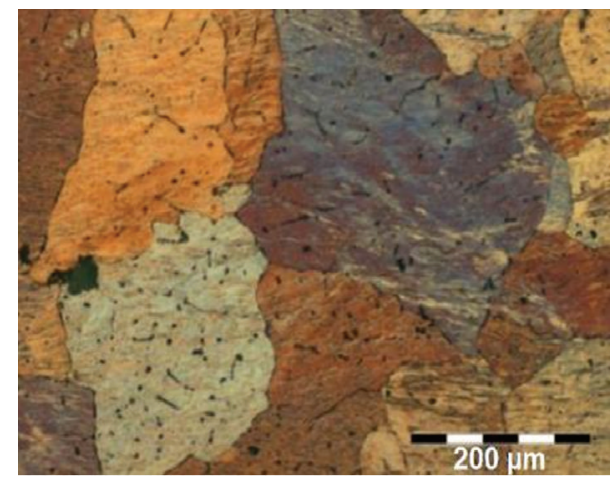

(b) AA1050 in N2 state

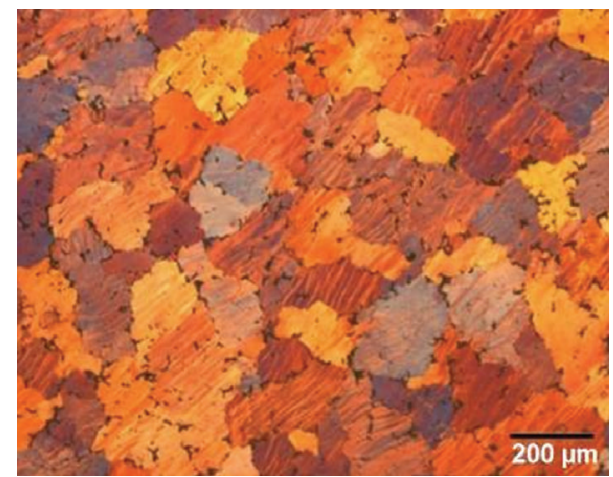

(d) AA5083 in N2 state

FIGURE 15: Grain size for the different starting materials.
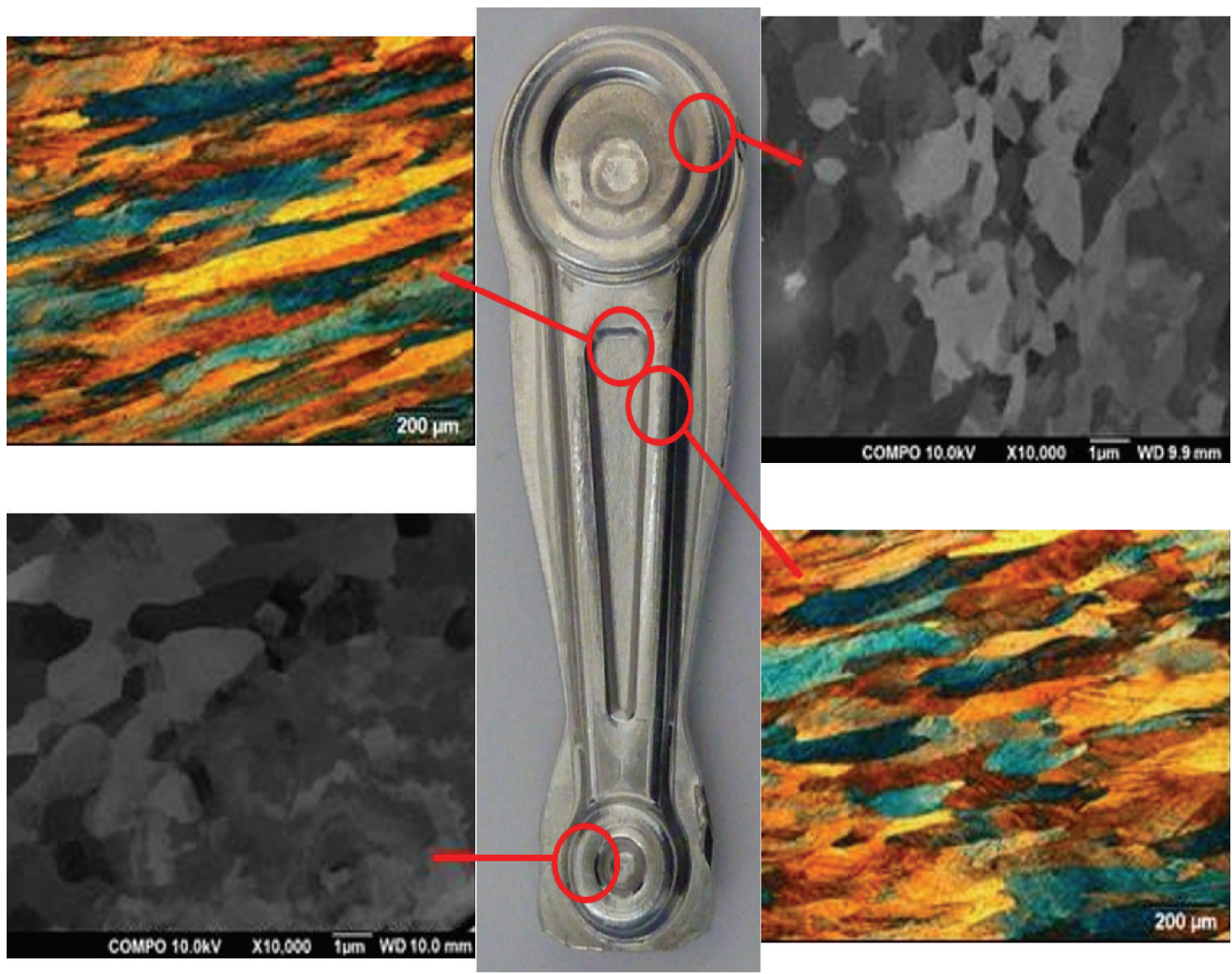

FIGURE 16: Optical and SEM micrographs at $25^{\circ} \mathrm{C}$ for AA1050 in N0 state. 

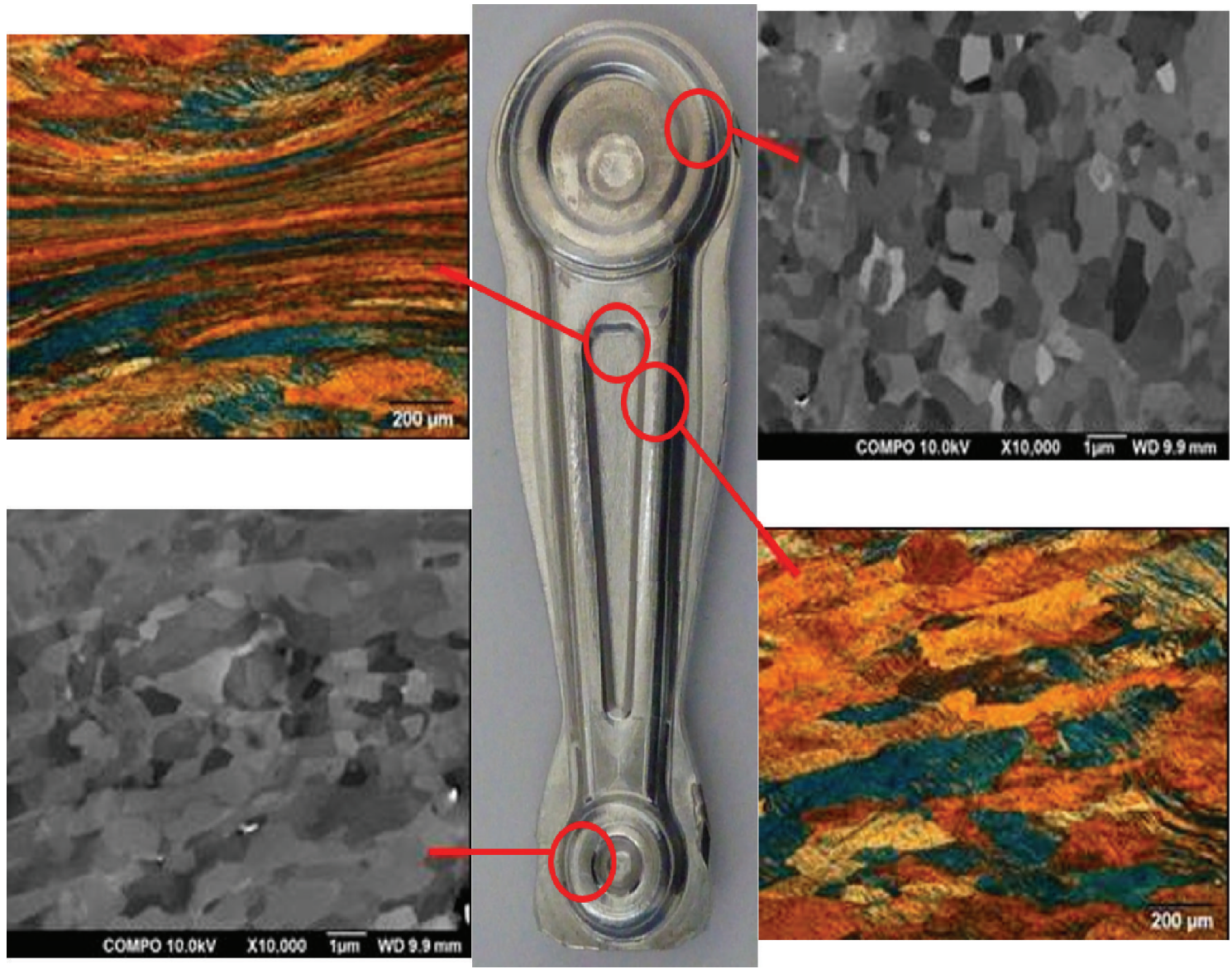

FIgURE 17: Optical and SEM micrographs at $25^{\circ} \mathrm{C}$ for AA1050 in N2 state.

In this case, the curves do not follow the same tendency as in the case of the non-ECAP'ed AA1050. This may be due to the anisotropy that the material presents after being ECAP'ed. The curve with the highest microhardness values corresponds to the forging at room temperature.

If the average values for each of the isothermal forging processes are compared, it is observed that hardness is higher for the previously ECAP'ed billets, as was expected. In this case, the difference implies an improvement of $20 \%$, as can be observed in Figure 12(c).

With respect to the results obtained for AA5083, it is observed in the case of the microhardness graphs for the non-ECAP'ed AA5083 forged that there is a very similar tendency for the three curves, as is shown in Figure 13(a). In this case, zone 1 is the one with the microhardness lowest value and zone 3 is the one with the highest value. The difference between the values obtained for the isothermal forging at $150^{\circ} \mathrm{C}$ and at $250^{\circ} \mathrm{C}$ turns out to be of $15 \%$. As the connecting rod forged at $150^{\circ} \mathrm{C}$ does not have defects, it is considered to be the optimum case when the highest mechanical properties are desired to be obtained in the case of non-ECAP'ed AA5083. It is observed from Figure 13(b) that the curves do not follow the same tendency as in the case of the ECAP'ed AA1050. At zone 1, the microhardness value is higher in the case of the connecting rod forged at $200^{\circ} \mathrm{C}$.
The improvement obtained when forging is carried out at $150^{\circ} \mathrm{C}$ instead of at $250{ }^{\circ} \mathrm{C}$ is of $23 \%$. Figure 13 (c) shows the average microhardness graphs for AA5083 in both N0 and $\mathrm{N} 2$, where the improvement achieved in the material when it is ECAP'ed is $15 \%$.

Figure 14 shows the simulations results in the case of the optimum forging temperature values for each alloy. In all these cases, it may be observed that the zone with the highest hardening value is that from the rib which is the closest to the head, where the connecting rod foot is the zone with the lowest strain value. These plastic strain results agree with those obtained in the case of microhardness.

The initial grain size of the two starting states previous to forging (N0 and N2) can be observed in Figure 15 for both aluminium alloys under consideration.

Figure 16 shows the microstructure for the AA1050 connecting rod starting from non-ECAP'ed material. In all the zones studied, a grain lengthening is observed where this is higher at the rib centre close to the head. In addition to this, the grain lengthening at the head zone is observed to be very small, that is to say, with a low strain value. The grain lengthening is even smaller at the foot of the connecting rod, where the grains are rather equiaxial.

Figure 17 shows the grain microstructure at different zones of the connecting rod forged from AA1050 ECAP'ed 

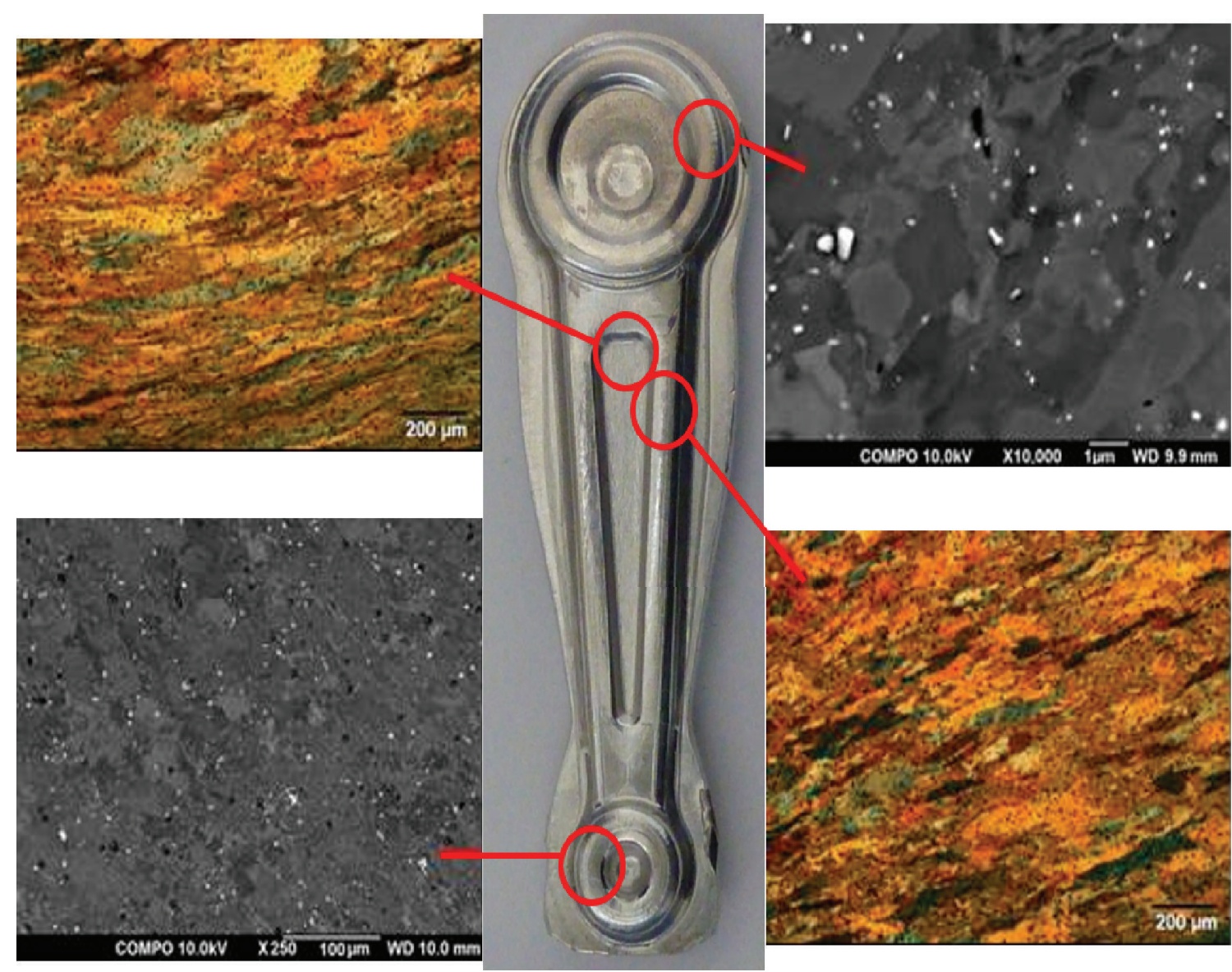

FIgURE 18: Optical and SEM micrographs at $150^{\circ} \mathrm{C}$ for AA5083 in N0 state.

twice (N2). As could be expected, at the centre of the rib close to the big head, the grain lengthening is higher than that obtained for N0 forged connecting rod, due to the previous deformation accumulated during the ECAP process. In addition, SEM micrographs show that the grain size is smaller and more equiaxial than that obtained for N0 forged connecting rod. A similar study is made in the case of the AA5083 connecting rod. The results obtained are the same as those obtained for AA1050 but taking into account that the initial grain size is lower. Again, the rib central zone is that with the highest elongation level in the grains, as can be observed in Figure 18. It is observed that the grains present a low strain value at the head zone whereas, at the connecting rod foot, there is practically no elongation and the grains are equiaxial. These results agree well with those obtained in the case of the simulations from Figure 14(c).

Finally, Figure 19 shows the grain microstructure at the different zones of the connecting rod forged from AA5083 ECAP'ed twice (N2). Again, the most highly deformed zone is located at the rib centre. In addition, it may be observed that the elongated grains after the forging process show deformation bands inside them which come from the previous ECAP processing. Similarly to AA1050, the head zones present a very low value of elongation because of the forging process but on the other hand there are a large number of deformation bands inside the grains. It is concluded that the forging temperature at $150^{\circ} \mathrm{C}$ is enough to achieve the material to flow adequately. This material flow allows us to have a good die filling and not to have cracks in the manufactured parts.

\section{Conclusions}

In this present research work, a study on the design and the manufacturing of a connecting rod is carried out using both the AA1050 and the AA5083 aluminium alloys previously ECAP'ed and subjected to an isothermal forging. It is demonstrated that it is possible to significantly improve the mechanical properties of the so-manufactured parts.

A considerable increase in the hardness of the connecting rod previously processed by equal channel angular pressing is obtained in relation to that forged from annealed material, where this occurs across all the range of temperature values taken into consideration in this present study. In the case of AA1050, this corresponds to an increase of approximately $20 \%$, with respect to the hardness attained in the nonECAP'ed material.

In the case of AA5083, an increase of approximately $15 \%$ is obtained in the whole temperature range, where $150^{\circ} \mathrm{C}$ turns out to be the most suitable temperature for manufacturing the parts.

In addition, it is demonstrated that it is possible to obtain connecting rods with submicrometric structure. Moreover, 


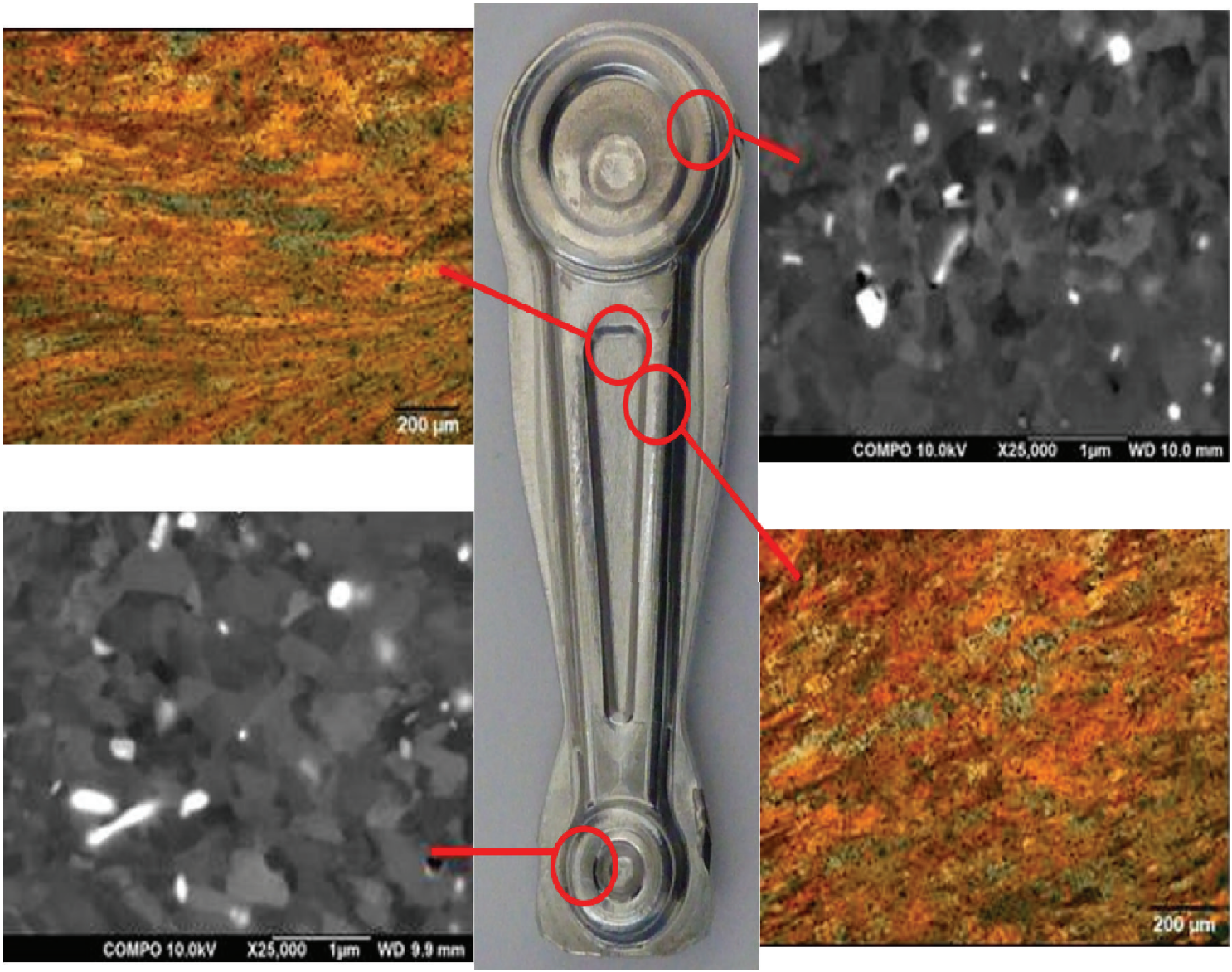

FIgURE 19: Optical and SEM micrographs at $150^{\circ} \mathrm{C}$ for AA5083 in N2 state.

lower temperatures are required for processing the parts by using isothermal forging, which may also lead to energetic savings as well as an improvement in the mechanical properties.

\section{Conflict of Interests}

The authors declare that there is no conflict of interests regarding the publication of this paper.

\section{Acknowledgment}

The authors of this present research work acknowledge the support given by the Ministry of Science and Innovation from Spain (now Ministry of Economy and Competitiveness), through both the Research Project DPI2010-18941 and the Research Project DPI2013-41954-P.

\section{References}

[1] V. M. Segal, "Plastic working of metals by simple shear," Russian Metallugical, vol. 1, pp. 99-105, 1981.

[2] G. Sakai, Z. Horita, and T. G. Langdon, "Grain refinement and superplasticity in an aluminum alloy processed by highpressure torsion," Materials Science and Engineering A, vol. 393, no. 1-2, pp. 344-351, 2005.
[3] J. Y. Huang, Y. T. Zhu, H. Jiang, and T. C. Lowe, "Microstructures and dislocation configurations in nanostructured $\mathrm{Cu}$ processed by repetitive corrugation and straightening," Acta Materialia, vol. 49, no. 9, pp. 1497-1505, 2001.

[4] J. Richert and M. Richert, "A new method for unlimited deformation of metals and alloys," Aluminium, vol. 62, no. 8, pp. 604-607, 1986.

[5] R. Kocich, A. MacHáčková, and F. Fojtík, "Comparison of strain and stress conditions in conventional and ARB rolling processes," International Journal of Mechanical Sciences, vol. 64, no. 1, pp. 54-61, 2012.

[6] G. J. Raab, R. Z. Valiev, T. C. Lowe, and Y. T. Zhu, "Continuous processing of ultrafine grained Al by ECAP-Conform," Materials Science and Engineering A, vol. 382, no. 1-2, pp. 30-34, 2004.

[7] A. Abdul-Latif, G. F. Dirras, S. Ramtani, and A. Hocini, "A new concept for producing ultrafine-grained metallic structures via an intermediate strain rate: experiments and modeling," International Journal of Mechanical Sciences, vol. 51, no. 11-12, pp. 797-806, 2009.

[8] R. Z. Valiev and T. G. Langdon, "Principles of equal-channel angular pressing as a processing tool for grain refinement," Progress in Materials Science, vol. 51, no. 7, pp. 881-981, 2006.

[9] B. Aour, F. Zaïri, M. Naït-Abdelaziz, J. M. Gloaguen, O. Rahmani, and J. M. Lefebvre, "A computational study of die geometry and processing conditions effects on equal channel angular extrusion of a polymer," International Journal of Mechanical Sciences, vol. 50, no. 3, pp. 589-602, 2008. 
[10] E. A. El-Danaf, "Mechanical properties, microstructure and texture of single pass equal channel angular pressed 1050, 5083, 6082 and 7010 aluminum alloys with different dies," Materials \& Design, vol. 32, no. 7, pp. 3838-3853, 2011.

[11] I. Puertas, C. J. L. Pérez, D. Salcedo, J. León, J. P. Fuertes, and R. Luri, "Design and mechanical property analysis of AA1050 turbine blades manufactured by equal channel angular extrusion and isothermal forging," Materials \& Design, vol. 52, pp. 774-784, 2013.

[12] J. H. Lee, S. H. Kang, and D. Y. Yang, "Novel forging technology of a magnesium alloy impeller with twisted blades of microthickness," CIRP Annals-Manufacturing Technology, vol. 57, no. 1, pp. 261-264, 2008.

[13] Y. G. Jin, H. M. Baek, S. K. Hwang, Y.-T. Im, and B. C. Jeon, "Continuous high strength aluminum bolt manufacturing by the spring-loaded ECAP system," Journal of Materials Processing Technology, vol. 212, no. 4, pp. 848-855, 2012.

[14] J. S. Choi, S. Nawaz, S. K. Hwang, H. C. Lee, and Y. T. Im, "Forgeability of ultra-fine grained aluminum alloy for bolt forming," International Journal of Mechanical Sciences, vol. 52, no. 10, pp. 1269-1276, 2010.

[15] M. Morehead, Y. Huang, and K. T. Hartwig, "Machinability of ultrafine-grained copper using tungsten carbide and polycrystalline diamond tools," International Journal of Machine Tools \& Manufacture, vol. 47, no. 2, pp. 286-293, 2007.

[16] G. Krállics, M. Horvath, and J. Nyirö, "Forming and machining of the nano-crystalline alloys," in Proceedings of the 2nd International Conference on Multi-Material Micro Manufacture, pp. 175-178, 2006.

[17] P. D. Toliya, R. C. Trivedi, and N. J. Chotai, "Design and finite element analysis of aluminium-6351 connecting rod," International Journal of Engineering Research \& Technology, vol. 2, no. 5, pp. 565-572, 2013.

[18] A. Kumar, K. Grover, and B. Budania, "Optimization of connecting rod parameters using CAE tools," International Journal of Latest Trends in Engineering and Technology, vol. 1, no. 3, pp. 98-104, 2012.

[19] H. Grass, C. Krempaszky, and E. Werner, "3-D FEM-simulation of hot forming processes for the production of a connecting rod," Computational Materials Science, vol. 36, no. 4, pp. 480489, 2006.

[20] D. Salcedo, C. Luis, I. Puertas, J. León, J. P. Fuertes, and R. Luri, "Analysis on the manufacturing of an AA5083 straight blade previously ECAE processed," Advances in Materials Science and Engineering, vol. 2013, Article ID 673247, 7 pages, 2013.

[21] International Organization for Standardization, ISO 65071:2005. Metallic Materials. Vickers Hardness Test. Part 1: Test Method, International Organization for Standardization, London, UK, 2005. 

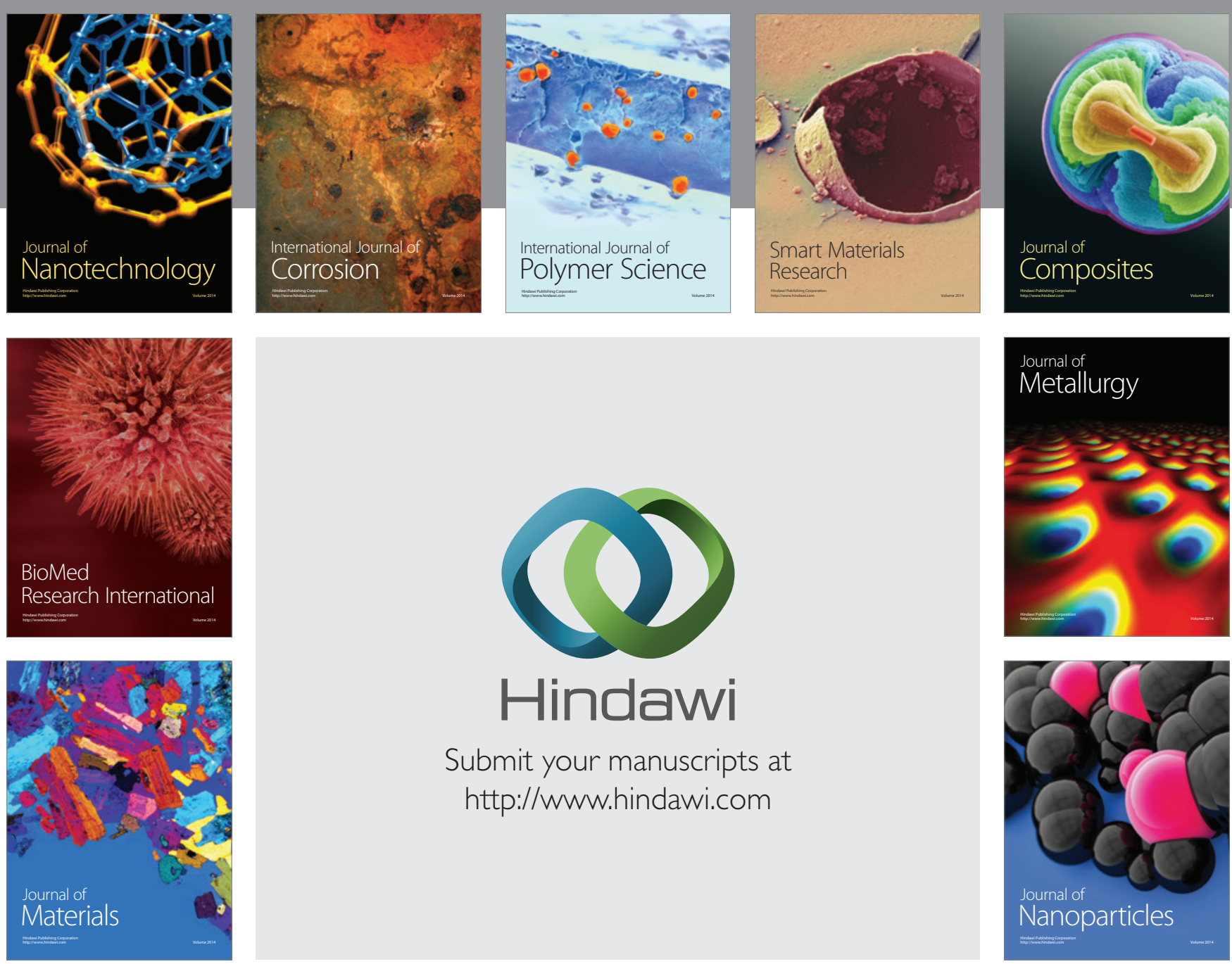

Submit your manuscripts at http://www.hindawi.com
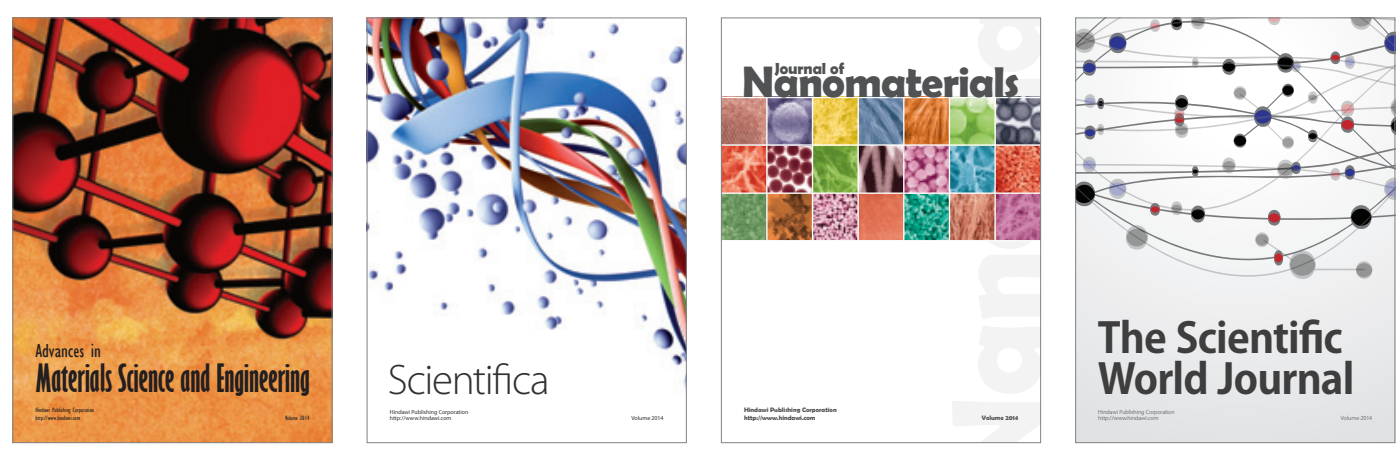

\section{The Scientific World Journal}
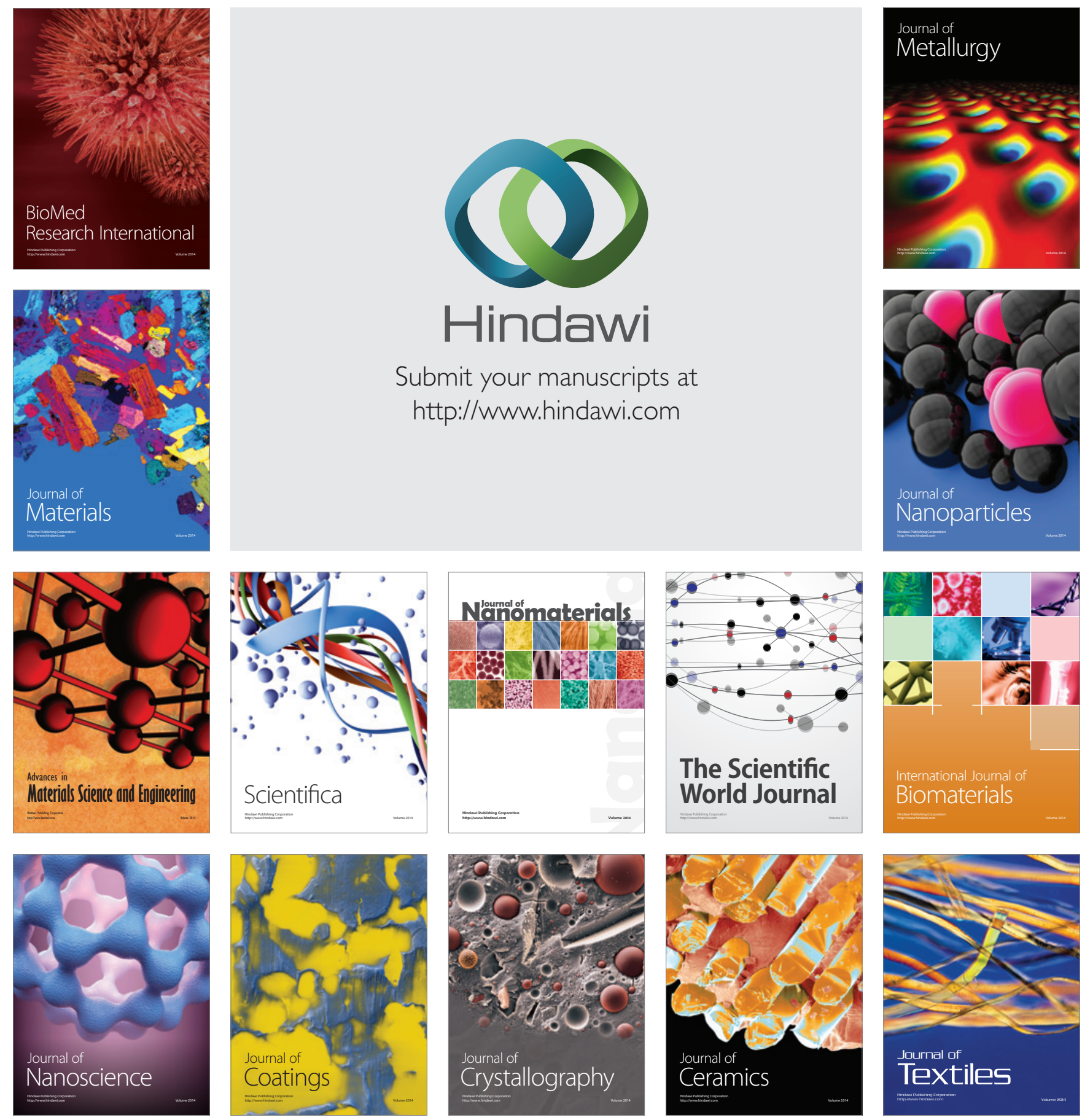